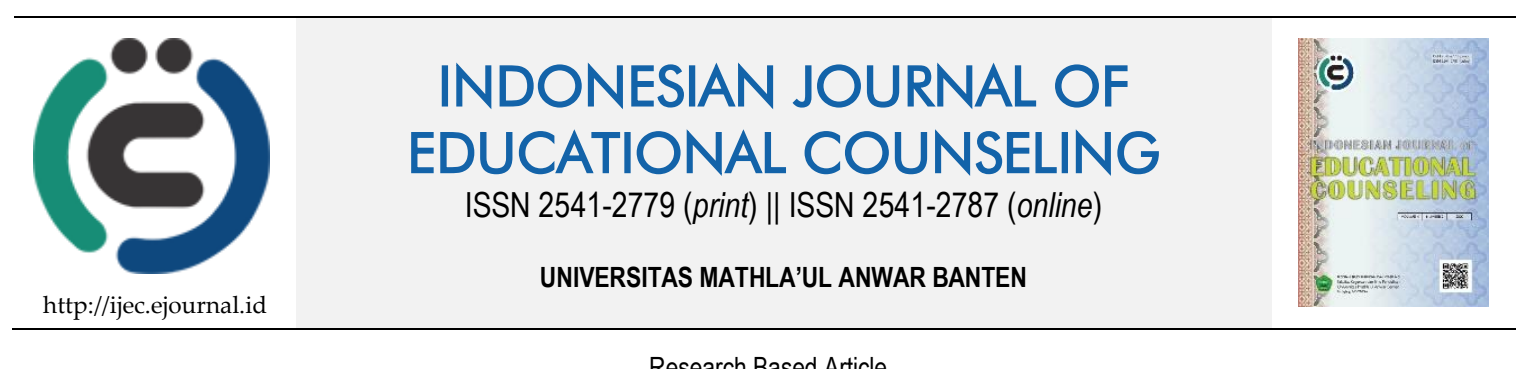

Research Based Article

\title{
Tembang Dolanan Jawa sebagai Media Pendidikan Karakter
}

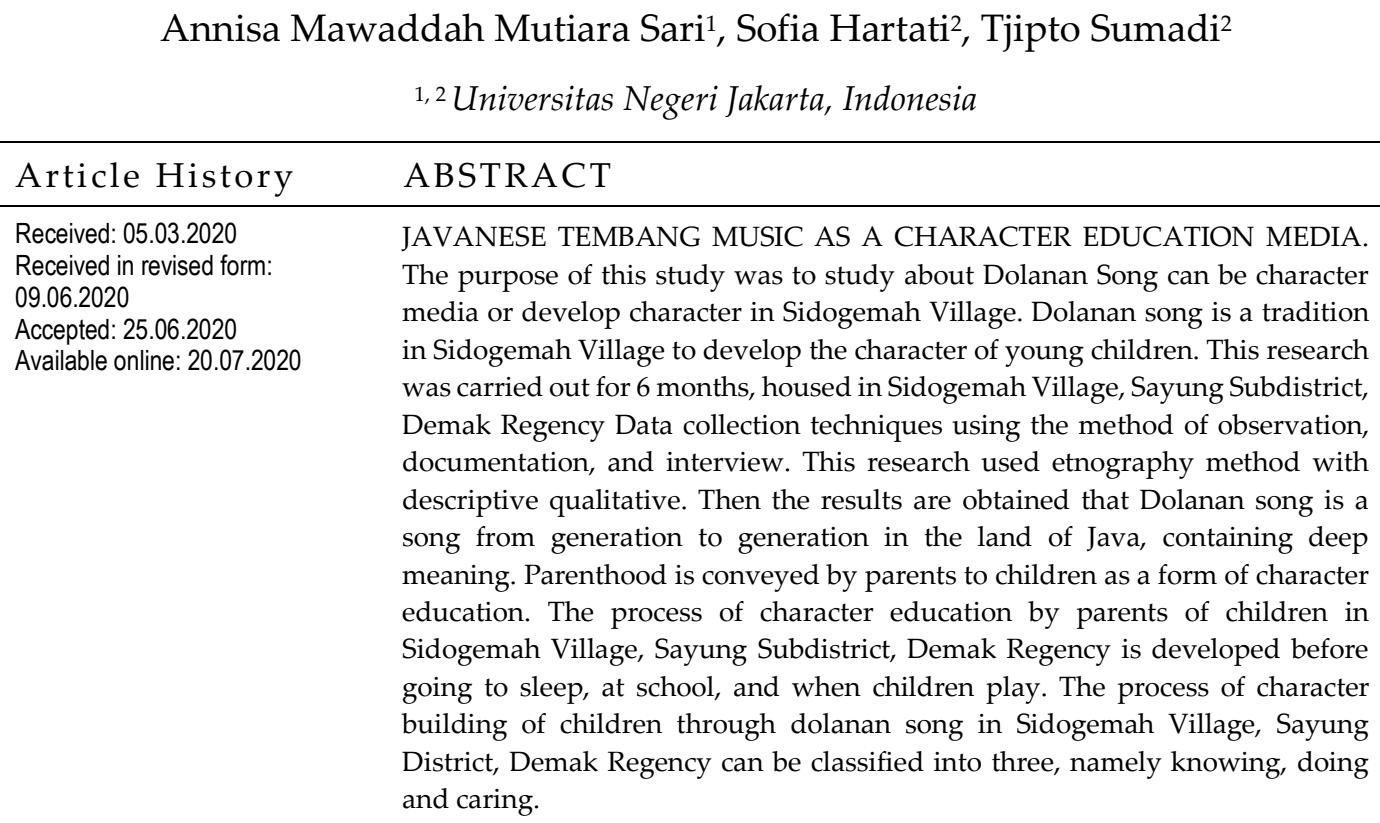

KEYWORDS: Elementary School, Humanism, Learning.

DOI: 10.30653/001.202042.142

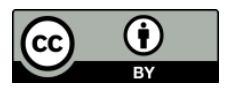

This is an open access article distributed under the terms of the Creative Commons Attribution 4.0 International License, which permits unrestricted use, distribution, and reproduction in any medium, provided the original work is properly cited. ○ 2020 Annisa Mawaddah Mutiara Sari, Sofia Hartati, Tjipto Sumadi.

\section{PENDAHULUAN}

Karakter merupakan suatu kepribadian berperilaku yang harus dimiliki oleh semua individu. Setiap individu memiliki keunikan dan ciri khas tersendiri yang berbeda dengan individu lainnya. Karakter yang diharapkan dimiliki oleh Bangsa Indonesia ialah karakter yang positif seperti jujur, sopan, rendah hati, senang membantu, percaya diri, gotong royong, disiplin, dan karakter baik lainnya yang perlu dibiasakan sejak usia dini agar menjadi sebuah kepribadian berkarakter yang baik.

Budaya merupakan pola kompleks pada perilaku atau tindakan manusia, diantaranya pikiran, ucapan, tindakan, yang ditransisikan dari generasi sebelumnya ke generasi selanjutnya. Sejalan dengan pendapat Healey dan Meadows mengungkapkan budaya sering dihubungkan dengan konsep akulturasi. Akulturasi dengan budaya mempunyai ikatan yang kuat yang di dalamnya termasuk keyakinan adat, bentuk-bentuk

${ }^{1}$ Corresponding author's address: Universitas Negeri Jakarta. Jl. Rawamangun Muka, RT.11/RW.14, Rawamangun, Kec. Pulo Gadung, Kota Jakarta Timur, Daerah Khusus Ibukota Jakarta 13220, Indonesia. Email: annisamawaddahmutiara_7516168223@mhs.unj.ac.id 
sosial serta sifat yang terdapat pada kelompok etnis maupun budaya (Healey \& Meadows, 2008, p. 26). Akulturasi merupakan suatu perpaduan budaya yang selanjutnya menghasilkan budaya baru tanpa menghilangkan unsur- unsur asli dalam budaya sebelumnya.

Atas Budaya dipandang sebagai cara hidup untuk bermasyarakat dimana mereka tinggal termasuk kode berpakaian mereka, adat istiadat, festival keagamaan, kebiasaan keluarga dan kegiatan rekreasi ataupun pekerjaan (Awde, 2009, p. 1). Dalam hal ini budaya tidak hanya berbicara mengenai nilai-nilai, norma, kepercayaan, tetapi juga berbicara tentang adab berpakaian sopan, kebiasaan masyarakat dalam hal hiburan atau rekreasi, maupun pekerjaan. Menurut Rachmawati (Rachmawati, 2010, pp. 61-76) musik sebagai salah satu kreasi estetik yang diyakini dapat memberikan kontribusi positif pada proses pembentukan karakter dan menganjurkan musik sebagai media dalam membangun pondasi karakter yang positif dan mulia, sehingga menyarankan untuk memasukkan musik sebagai bagian dari instruksional program si setiap tahap pendidikan, yang paling dalam pendidikan anak usia dini. Sama halnya yang terjadi di masyarakat di Desa Sidorawuh Kecamatan Sayung Kabupaten Demak. Masyarakat masih melestarikan adat atau kebiasaan nembang Jawa.

Hasil observasi awal pada tanggal 30 November 2017, peneliti merasa anak di Desa Sidogemah Kecamatan Sayung Kabupaten Demak memiliki perbedaan dengan anak di desa lain. Saat bermain di lingkungan sekolah, di tempat ngaji, di rumah anak-anak sering nembang jawa. Anak-anak sudah terbiasa mendengarkan orang tua mereka nembang jawa dalam berbagai kegiatannya, pada saat anak bermain, belajar, mengaji atau pun saat tidur. Dalam menembangkan tembang dolanan jawa pengucapan dan ekspresi merekapun sangat menghayati. Di Sidogemah selain mengenalkan karakter di sekolah formal, anak usia dini juga belajar melalui kegiatan seni tembang yang dilakukan dan sudah menjadi kebiasaan warga setempat. Orang dewasa menyadari bahwa tembang dolanan jawa ini dapat dijadikan media pendidikan karakter karena di dalam syair tembang mempunyai banyak nilai-nilai positif yang terkandung didalamnya. Dalam penyampaian makna dalam syair tembang dolanan jawa orang tua atau orang dewasa lainnya menggunakan bahasa yang mudah dipahami anak-anak sehingga anak paham makna nilai karakter yang terkandung dalam tembang dolanan jawa

Karakter anak di desa sidorawuh dapat dikatakan bagus, apalagi pada karakter religiusnya. Ini dapat dibuktikan ketika observasi awal anak-anak sudah mulai belajar menutup auratnya, saat sore hari anak-anak berangkat ke langgar untuk mengaji dan ketika adzan sholat anak-anak pergi ke masjid bersama orang tua mereka. Bahkan. saat sholat shubuh pun anak-anak ikut pergi ke masjid. Sedangkan di daerah lain sudah mulai tergerus oleh perkembangan jaman yang membuat anak lebih suka berdiam diri dirumah bermain gadget. Orang tua pun menjelaskan kepada peneliti bahwa alangkah baiknya apabila mengajarkan taat pada ajaran agama islam sejak anak usia dini. Anak-anak di Desa Sidorawuh Kecamatan Sayung Kabupaten Demak memiliki sikap disiplin, bertanggung jawab dan sopan. Keberhasilan dalam mempertahankan sikap baik tersebut karena masih memegang teguh tradisi jawa yang telah turun-temurun sampai saat ini. Salah satunya adalah menembangkan tembang jawa kepada anak-anak yang mempunyai banyak nilai-nilai karakter yang baik, diantaranya sikap religus, berbuat jujur, bertanggung jawab, sopan, perjuangan dan semangat. 
Tembang dolanan termasuk tembang atau lagu gagrak anyar, yang tidak mengikuti aturan gatra, guru lagu, guru wilangon, dan dhong-dhing. Lagu ini biasa dinyanyikan oleh anak terutama di pedesaan sambil bermain bersama dengan teman - temannya dan bisa diiringi dengan irama gendhing. Melalui lagu dolanan, anak - anak diperkenalkan bab jenis - jenis hewan, tetumbuhan, kehidupan sosial, lingkungan alam, dan sebagainya. Kadangkala tembang dolanan juga dinyanyikan oleh waranggana saat suasana tertentu dalam pagelaran wayang (Farida et al., 2016, p. 9).

Menurut Boyer dalam (Sousa, 2012, p. 248) bahwa kualitas suatu budaya atau masyarakat dapat diukur dari musik, tarian, drama, artitektur, seni visual, dan literature yang dimilikinya, sehingga anak-anak harus diberikan pengetahuan dan pemahaman mengenai hasil-hasil karya kebudayaan yang paling terkemuka. Kebudayaan yang memiliki nilai-nilai kearifan lokal sudah sepantasnya dilestarikan dan sekaligus di wariskan kepada anak-anak sejak usia dini, selanjutnya Vygostky dalam (Sandra, 2019, p. 19) mengatakan bahwa budaya memiliki alat-alat budaya, yang disebut juga sebagai alat psikologis yaitu benda-benda, tanda-tanda dan system yang dikembangkan oleh manusia dari waktu ke waktu dan dalam masyarakat untuk membantu pemikiran, dimana salah satu dari alat-alat budaya tersebut adalah music dan seni. Pentingnya pendidikan karakter melalui budaya karena semua anak berasal dari budaya yang telah mengembangkan alat-alat budaya mereka sendiri. Anak-anak membutuhkan akses ke alat-alat yang memungkinkan mereka untuk menggunakan dan memahami dunia. Pendidikan karakter dilakukan melalui budaya, menurut Vygostky tertarik pada bagaimana pengetahuan yang baik dibangun dan diwariskan dari satu generasi lain.

Di Jawa memiliki lagu-lagu yang dipergunakan untuk mengasuh anak usia dini. Lagu-lagu yang dipergunakan bagi anak usia dini pada umumnya memiliki syair yang mendidik dan dengan irama yang bermacam-macam. Ada irama yang lembut, ada pula irama yang riang gembira. Lagu-lagu yang digunakan untuk anak usia dini di Jawa dikenal dengan nama tembang dolanan jawa. Tembang dolanan jawa oleh masyarakat Jawa di desa Sidorawuh yang dilantunkan oleh orang tua pada saat mengasuh anak dan dilantunkan anak-anak saat bermain dengan teman sebaya dipercaya dapat dijadikan sebagai media pendidikan karakter pada anak, karena saat orang tua dan anak melantunkan tembang dolanan jawa terjalin hubungan yang hangat antara orang tua dengan anak dan anak dengan teman sebaya, sehingga pada diri anak tumbuh rasa percaya diri bahwa orang tuanya, teman sebaya dan lingkungannya sangat menyayanginya.

Nilai-nilai karakter yang perlu ditanamkan kepada anak usia dini Desa Sidogemah adalah nilai-nilai universal yang mencangkup agama, tradisi dan budaya. Nilai ini harus menjadi perekat bagi seluruh anggota masyarakat walaupun berbeda latar belakang budaya, suku, agama dan sosial ekonomi. Selanjutnya menurut (Megawangi, 2007, p. 93) nilai karakter yang layak diajarkan pada anak yaitu:

1) Cinta tuhan dan segenap ciptaanya

2) Kemandirian dan tanggung jawab

3) Kejujuran atau amanah dan bijaksana

4) Hormat dan santun

5) Dermawan, suka menolong dan gotong royong

6) Percaya diri, kreatif dan pekerja keras 
7) Kepemimpinan dan keahlian

8) Baik dan rendah hati

9) Toleransi, kedamaian, dan kesatuan.

Tradisi tembang dolanan jawa oleh masyarakat desa Sidorawuh masih melestarikan budaya tersebut sampai saat ini sebagai media pendidikan karakter pada anak usia dini, karena tembang dolanan jawa memiliki sifat riang gembira, lucu, dan mendidik, sehingga disukai oleh anak usia dini. Kuhlmaan menyebutkan bahwa saat anak merasa positif terhadap lingkungan pembelajarannya, endorphin dilepaskan di dalam otak, dan edorfin ini menghasilkan rasa gembira dan memicu lobus frontal, sehingga aktivitas belajar lebih menyenangkan dan lebih berhasil (Sousa, 2012). Dengan demikian, anak merasa gembira maka pendidikan karakter pada anak usia dini akan menjadi lebih mudah dilakukan. Sehingga, peneliti melakukan penelitian tentang pendidikan karakter anak di Desa Sidogemah Kecamatan Sayung Kabupaten Demak.Peneliti tertarik untuk mengkaji lebih dalam tentang “Tembang Dolanan Jawa Sebagai Media Pendidikan Karakter".Melalui metode kualitatif dengan pendekatan etnografi.

\section{METODE}

Metode yang digunakan penelitian ini adalah penelitian kualitatif dengan pendekatan etnografi yang bertujuan untuk meneliti kondisi objek yang alamiah, peneliti sebagai instrument kunci, teknik pengumpulan data dilakukan secara triangulasi, analisis data bersifat induktif dan penelitian kualitatif lebih menekankan makna dari pada generalisasi (Sugiyono, 2011). Hal ini berkaitan dengan penelitian kualitatif yang digunakan untuk memperoleh pemahaman secara mendalam tentang sikap, kepercayaan, motivasi dan prilaku tertentu (Handini, 2012, p. 22).

Tabel 1. Sembilan Hubungan Semantik

\begin{tabular}{|c|c|}
\hline Hubungan & Bentuk \\
\hline Termasuk & $\mathrm{X}$ adalah termasuk sejenis $\mathrm{Y}$ \\
\hline Bagian & $\mathrm{X}$ adalah bagian dari $\mathrm{Y}$ \\
\hline Sebab akibat & $\mathrm{X}$ adalah akibat dari $\mathrm{Y}$ \\
\hline Rasional & $\mathrm{X}$ adalah alasan melakukan $\mathrm{Y}$ \\
\hline Tempat & $\mathrm{X}$ adalah tempat melakukan $\mathrm{Y}$ \\
\hline Fungsi & $\mathrm{X}$ digunakan untuk $\mathrm{Y}$ \\
\hline Cara-Tujuan & X adalah cara untuk melakukan $Y$ \\
\hline Urutan & $\mathrm{X}$ adalah langkah dari $\mathrm{Y}$ \\
\hline Memberi atribut & $\mathrm{X}$ adalah atribut $\mathrm{Y}$ \\
\hline
\end{tabular}

Penelitian ini dilaksanakan di Desa Sidogemah Kecamatan Sayung Kabupaten Demak. Peneliti melakukan penelitian di Desa Sidorawuh di karenakan Tembang Dolanan Jawa masih menjadi tradisi dalam kehidupan di masyarakat dan sering ditembangkan kepada anak usia dini. Tembang Dolanan Jawa ditembangkan pada kehidupan anak di saat masih dalam kandungan, pada waktu mengasuh anak usia dini, pada waktu menidurkan anak, pada anak-anak bermain di lingkungan rumah maupun di lingkungan sekolahan sebagai media perkembangan nilai karakter untuk anak usia dini.

Penelitian ini lebih mengutamakan proses yang dilaksanakan oleh peneliti dari pada hasil selama masa penelitian. Untuk mengetahui proses yang mendalam dan akurat 
dibutuhkan waktu yang relative lama jika dibandingkan dengan penelitian lainnya yaitu antara 6 sampai 24 bulan (Sugiyono, 2011, p. 384). Observasi awal dilakukan pada bulan Desember 2017. Penelitian ini dilaksanakan sesuai dengan penelitian kualitatif etnografi dimana peneliti melakukan sebanyak mungkin berinteraksi dengan subjek penelitian di Desa Sidorawuh Kelurahan Sidogemah Kecamatan Sayung Kabupaten Demak.

\section{HASIL DAN PEMBAHASAN}

\section{Karakter Anak Usia Dini di Desa Sidogemah Kecamatan Sayung Kabupaten Demak}

Instrumen yang telah diuji validitas dan reliabilitasnya akan digunakan untuk mengukur perilaku sopan santun anak. Skor total hasil pengukuran baik pada kelompok eksperimen dan kelompok kontrol, kemudian dihitung untuk melihat ukuran pemusatan dan penyebaran datanya.

Berdasarkan analisis hasil penelitian, maka dapat dirumuskan teori substantif sebagai berikut "apabila anak usia dini menunjukkan tindakan perilaku berdasarkan keempat aspek di atas diantaranya cinta Tuhan Yang Maha Esa, jujur, adil, percaya diri, mandiri, tanggung jawab, kerja keras, kreatif, rendah hati, toleransi, tolong menolong, kerjsama, gotong royong, hormat, kepemimpinan, peduli lingkungan dan cinta bangsa dan tanah air maka dapat disimpulkan bahwa anak-anak di Desa Sidogemah mempunyai karakter yang baik".

Hasil temuan penelitian juga mendapatkan data tentang perilaku negatif anak usia dini di Desa Sidogemah. Perilaku negatif itu diantaranya sikap menganggu, mubazir, tidak jujur, dan merusak lingkungan. Perilaku negatif yang peneliti temukan hanya sedikit saja karena sejak kecil anak memang sudah diajarkan untuk bersikap sesuai ajaran agama Islam. Anak-anak yang mempunyai sikap negatif ini rata-rata anak yang orangtuanya bekerja di pasar, sehingga anak mudah mencontoh perilaku-perilaku kurang baik yang dilihatnya saat menemani orangtua berjualan di pasar.

\section{Proses Pendidikan Karakter Anak Oleh Orang Tua Melalui Tembang Dolanan}

Lingkungan pertama yang membentuk karakter anak adalah lingkungan keluarga, oleh karena itu diperlukan strategi yang tepat agar anak dapat menyerap nilai-nilai. Seperti masyarakat di Desa Sidogemah, salah satu cara yang dilakukan untuk mengenalkan karakter pada anak usia dini adalah melalui tembang dolanan. Tembang dolanan dinyanyikan ketika orang tua akan menidurkan anak dimulai semenjak anak masih kecil, kemudian guru di sekolah juga menyanyikan tembang dolanan dan ketika anak-anak sedang bermain. Ini adalah salah cara yang paling awal untuk mengenalkan anak pada nilai-nilai yang ada disekitarnya.

Menurut Shuncke dalam bukunya yaitu Elementary Social Studies bahwa seorang anak untuk mendapatkan pemahaman di lingkungan sosial nya terdapat tiga cara yang berkualitas yaitu pengetahuan (knowing), perilaku (doing), dan peduli (caring) (Schuncke, 1988). Agar anak mempunyai pengetahuan maka hak yang perlu dilakukan yaitu mengenalkan anak dengan nilai-nilai karakter itu sendiri. Langkah pengenalan itu dapat dengan cara pembiasaan dan juga mencontohkannya kepada anak. Hal ini sesuai dengan pendapat Walgito bahwa pembentukan menjadi karakter dibagi menjadi tiga cara yaitu (1) pembiasaan diri anak untuk melakukan perilaku yang diharapkan sehingga terbentukah perilaku tersebut, (2) pengertian kepada anak mengenai perilaku yang ingin dibentuk, (3) menjadi model dari perilaku yang yang ingin dibentuk (UGM, 2017, P. 9). 
Pengetahuan juga bisa didapatkan anak dari kebiasaan mendengarkan lagu atau cerita tentang perilaku yang ingin diterapkan kepada anak. Seperti yang dilakukan oleh masyarakat Jawa di Desa Sidogemah, agar anak mempunyai pengetahuan tentang moral maka selalu didengarkan tembang dolanan yang sarat akan nilai-nilai kebajikan.

Berdasarkan analisis hasil penelitian, maka dapat dirumuskan teori substantif sebagai berikut "apabila ketiga komponen karakter Pengetahuan (knowing), Perilaku (doing), dan Peduli (caring) terdapat dalam proses menyanyikan Tembang dolanan oleh orang tua kepada anak maka dapat disimpulkan bahwa tembang dolanan bisa menjadi salah satu bentuk kegiatan dalam mengembangkan karakter anak". Karena Proses pendidikan karakter pada Tembang dolanan melalui 3 tahap di atas maka dapat dikatakan bahwa Tembang dolanan adalah salah satu cara untuk menanamkan karakter pada anak usia dini

\section{Nilai-Nilai Karakter-Karakter Yang Terkandung Dalam Tembang Dolanan}

Banyak cara yang dapat dilakukan oleh orang tua dalam mengenalkan karakter kepada anak. Salah satu cara yang dilakukan oleh masyarakat di Desa Sidogemah yaitu dengan menyanyikan tembang dolanan sebelum anak tidur. Menurut Kasmi dendang diartikan sebagai nyanyian, yang berarti mengeluarkan suara hati atau menyampaikan apa yang terasa dalam hati kepada seseorang dengan bernyanyi. Hal tersebut dapat berupa gembira, kecewa, lucu, rasa cinta, sedih ataupun ungkapan syukur kepada Sang Pencipta. (Kasmi, 2017,3) Tembang dolanan berarti nyanyian masyarakat jawa yang biasanya berirama merdu yang berisi nilai-nilai yang ingin disampaikan.

Kebiasaan menyanyikan tembang dolanan ini sudah ada sejak lama, agar anak cepat tertidur maka orang tua menyanyikan tembang dolanan yang merupakan salah satu kesenian masyarakat Jawa, selanjutnya guru menembangkannya di sekolah dan ketika anak-anak sedang bermain. Ratna menyebutkan bahwa karya sastra, seni dan budaya sebenarnya mempunyai peranan penting dalam pendidikan karakter. Alasannya adalah di dalam karya tersebut terdapat berbagai narasi yang berisi contoh dan teladan, hikmah dan nasehat, ganjaran atau hukuman yang berkaitan dengan pendidikan karakter.

Berdasarkan analisis hasil penelitian dengan beberapa teori yang ada, maka dapat dirumuskan teori substantif sebagai berikut "apabila tembang dolanan yang dinyanyikan oleh orang tua mempunyai makna spiritual, nilai-nilai individu yang mesti dipunya anak, nilai-nilai sosial serta nilai-nilai yang mesti dilakukan anak terhadap lingkungan tempatnya tinggal maka tembang dolanan merupakan salah satu cara untuk menanamkan karakter pada anak usia dini di Desa Sidogemah". Dalam penemuan penelitian ditemukan bahwa hampir semua karakter anak usia dini terdapat di dalam Tembang dolanan yang dinyanyikan masyarakat Desa Sidogemah.

\section{Lirik Tembang Dolanan Di Desa Sidogemah Kecamatan Sayung Kabupaten Demak Yang Dapat Menstimulasi Perkembangan Karakter Anak}

Tembang dolanan di Desa Sidogemah terdiri atas tembang dolanan dengan lirik yang sudah dibakukan. Lirik tembang dolanan memegang peranan penting dalam pendidikan karakter anak usia dini di Desa Sidogemah. Karena lirik sangat berpengaruh terhadap nilai-nilai yang ingin disampaikan kepada anak.

Ini juga sejalan dengan penelitian yang dilakukan oleh Sugiyo dan Purwastuti juga melakukan penelitian tentang pengembangan model pendidikan karakter terpadu berdasarkan kearifan lokal di sekolah dasar di Bantul, Yogyakarta, Indonesia. Salah satu 
kegiatan yang dilakukan adalah menyanyikan lagu tradisional yang disebut "Cublakcublak Suweng" memadukan nilai cinta, kejujuran, dan tanggung jawab. Lagu ini mempunyai lirik yang ceria sehingga anak yang mendengarkannya juga bersemangat. lagu "Cublak-cublak Suweng" merupakan salah satu tembang dolanan dari Desa Sidogemah. Liriknya sudah dibakukan menjadi sebuah lagu yang ceria oleh penulis lagunya. Tetapi ada juga lirik dendang lagu baku yang turun temurun tapi tidak diketahui penciptanya, seperti lagu dendangkan anak.

Berdasarkan analisis hasil penelitian dengan beberapa teori yang ada, maka dapat dirumuskan teori substantif sebagai berikut "apabila tembang dolanan yang dinyanyikan oleh orang tua, guru, dan anak itu sendiri mempunyai lirik sederhana, lirik ceria dan mengandung nilai moral maka Tembang dolanan dikatakan dapat menstimulus perkembangan karakter anak".

\section{Waktu Tembang Dolanan Dinyanyikan di Desa Sidogemah Kecamatan Sayung Kabupaten Demak}

Tembang dolanan yang peneliti temukan di Desa Sidogemah merupakan salah satu tembang pengantar tidur yang dinyanyikan oleh orang tua maupun oleh nenek dari anak atau lagu penyemangat bagi guru serta anak itu sendiri.

Ketika anak mendengarkan tembang dolanan maka kata-kata tersebut akan terekam dalam ingatannya karena lirik tembang dolanan tersebutlah yang terkahir di dengarkan salah satunya pada saat anak sebelum dia tidur. Selain itu irama tembang dolanan juga merdu sehingga disukai anak. Seperti yang disampaikan oleh Collins bahwa "the study found that exposure to the broader benefits of music education to brain development heightened levels of confidence, commitment and responsibility" (Collins, 2015, 2). Musik menstimulus otak dalam mengembangkan dan meningkatkan rasa percaya diri, berkomitmen dan mempunyai tanggung jawab yang tinggi. Musik akan menjadi salah satu media yang dapat mengembangkan karakter anak apabila dilakukan dengan rutin dan mendengarkan dendang yang mempunyai nilai yang positif pada anak.

Berdasarkan analisis hasil penelitian dengan beberapa teori yang ada, maka dapat dirumuskan teori substantif sebagai berikut "apabila tembang dolanan selalu dinyanyikan oleh orang tua sebelum anak tidur maka tembang dolanan tersebut berperan dalam pendidikan karakter pada anak usia dini".

\section{Alasan Masyarakat Desa Sidogemah Memilih Tembang Dolanan Jawa}

Tembang dolanan jawa memiliki makna yang dalam pada setiap syairnya hal ini menjadikan masyarakat Desa Sidogemah menjadikan tembang dolanan jawa sebagai perantara media pengembangan karakter anak usia dini, seperti menurut Jawa Tembang dapat digunakan sebagai media penanaman karakter.

Tembang ini dinyanyikan oleh orang tua, guru, dan anakpun tanpa sadar menyanyikan tembang dolanan jawa ketika bermain. Tembang dolanan jawa memiliki makna dan bahasa kromo sehingga anak bisa belajar bahasa Kromo tanpa sadar, tanpa sadar anak merealisasikan apa yang ditembangkan oleh masyarakat sekitar.

Sejalan dengan pendapat Mei-Ju, Chen-Hsin, Pin-Chen dalam penelitiannya yang berjudul "The Beauty of Character Education on Preschool Children's Parent-Child Relationship" mengungkapkan bahwa pendidikan karakter harus dimulai sejak sedini mungkin (MeiJu, Chen-Hsin, \& Pin-Chen, 2014). Dengan memberikan tembang dolanan jawa, 
masyarakat Desa Sidogemah anak-anak dapat menyerap apa yang disampaikan dalam tembang dolanan jawa.

Berdasarkan analisis hasil penelitian dengan beberapa teori yang ada, maka dapat dirumuskan teori substantif sebagai berikut "apabila tembang dolanan selalu dinyanyikan oleh masyarakat Desa Sidogemah maka anak usia dini dapat menyerap apa yang di tembangkan".

\section{SIMPULAN}

Berdasarkan penelitian yang dilakukan, maka dapat disimpulkan bahwa tembang dolanan jawa menjadi media pengembangan karakter di desa Sidogemah. Tembang dolanan merupakan tembang yang dinyanyikan secara turun temurun di tanah Jawa, berisikan makna yang dalam. Secara turun-temurun disampaikan oleh orang tua terhadap anak sebagai bentuk pendidikan karakter. Proses pendidikan karakter tembang dolanan oleh orang tua terhadap anak di Desa Sidogemah Kecamatan Sayung Kabupaten Demak ditembangkan sebelum mau tidur, pada saat di sekolah, dan pada saat anak bermain. Proses terbentuknya karakter anak melalui tembang dolanan di Desa Sidogemah Kecamatan Sayung Kabupaten Demak dapat diklasifikasikan menjadi tiga yaitu pengetahuan (knowing), perilaku (doing) dan peduli (caring).

\section{REFERENSI}

Awde, N. (2009). The influence of cultural values on the parent-child interaction patterns of families from an Asian background. Arecls, 6, 1-17.

Farida, U., Sutiyem, Handono, S., Karyono, Shintya, Pressanti, D. A., \& Inayati, I. (2016). Tembang dolanan sebuah refleksi filosofi Jawa. Semarang: Balai Bahasa Jawa Tengah.

Handini, M. C. (2012). Metodologi penelitian untuk pemula. Jakarta: FIP Press.

Healey, G. K., \& Meadows, L. M. (2008). Tradition and culture: An important determinant of Inuit women's health. International Journal of Indigenous Health, 4(1), 25-33.

Megawangi, R. (2007). Pendidikan karakter solusi yang tepat untuk membangun bangsa. Bogor: Indonesia Heritage Foundation.

Mei-Ju, C., Chen-Hsin, Y., \& Pin-Chen, H. (2014). The beauty of character education on preschool children's parent-child relationship. Procedia-Social and Behavioral Sciences, 143, 527-533. https://doi.org/10.1016/j.sbspro.2014.07.431

Rachmawati, Y. (2010). The role of music in character building. International Journal of Learning, 17(9), 61-76.

Sandra, S. (2019). Introducting Vygotsky: A guide for practitioners and students in early Years Education. London and New York: Routledge.

Schuncke, G. M. (1988). Elementary social studies knowing, doing, caring. New York: Macmillan Publishing Company.

Sousa, D. A. (2012). Bagaimana otak belajar. Jakarta: Indeks.

Sugiyono. (2011). Metode penelitian kombinasi (Mixed methods). Bandung: Alfabeta. 